\title{
Differences in intra-tree variation in spiral grain angle for radiata pine
}

\author{
Michael S Watt ${ }^{1 *}$, Mark O Kimberley ${ }^{2}$, Jonathan J Harrington ${ }^{2}$, Mark JC Riddell ${ }^{2}$, Dave J Cown ${ }^{2}$ and John R Moore ${ }^{2}$
}

\begin{abstract}
Background: Spiral grain angle (SGA) is an important factor affecting the distortion and utilisation of solid timber. Little research has investigated how SGA varies at a fine scale within trees and whether this fine-scale threedimensional variation is similar between genotypes. The objectives of this research were to (i) characterise threedimensional variation in SGA within stems and clones, and (ii) understand how intra-stem variation in SGA varies between genotypes.
\end{abstract}

Methods: Detailed measurements of SGA were taken from 12 radiata pine (Pinus radiata D. Don) clones. Analyses were undertaken to characterise variation in three dimensions and determine if this variation significantly differed between genotypes.

Results: Spiral grain varied significantly with distance from the pith, showing a sharp initial increase with distance from the pith, followed by a gradual decline. Values of SGA increased significantly with height up the stem, reaching a maximum at ca. $5 \mathrm{~m}$. Circumferential variation in SGA showed no significant trend. There was significant variation in mean SGA between clones; however, the within tree patterns in SGA did not significantly vary between clones.

Conclusion: If further research confirms the uniformity of within tree patterns in SGA between clones this may greatly simplify efforts to model three-dimensional variation in SGA.

Keywords: Pinus radiata; Radiata pine; Spiral grain

\section{Background}

One of the factors that has the greatest influence on the utilisation of wood from a wide range of species, including radiata pine (Pinus radiata D. Don), is lack of dimensional stability caused by spiral grain (Johansson et al. 1994). Spiral grain angle (SGA) is defined as the orientation of fibres (tracheids) with reference to the longitudinal axis of the tree stem. The relatively high values of SGA found in radiata pine (Ormarsson and Cown 2005), particularly in corewood, can cause twist in dry timber, distortion in plywood sheets, surfacing problems during machining (Tsehaye and Walker 1995; Ekevad 2005) and are a major cause of drying degrade in radiata pine and other conifers (Haslett and McConchie 1986; Haslett et al. 1991; Danborg 1994). Cown et al. (1995) reported that twist in radiata pine is responsible

\footnotetext{
* Correspondence: michael.watt@scionresearch.com

'Scion, P.O. Box 29237, Fendalton, Christchurch, New Zealand

Full list of author information is available at the end of the article
}

for at least $90 \%$ of the instability of affected radiata pine timber produced in fast-grown plantations in New Zealand. Similarly, Sorensson and Lausberg (1996) demonstrated that a decrease in spiral grain in juvenile wood of 3 degrees was sufficient to reduce rejection rates for twist from $12 \%$ to $5 \%$, and would save the New Zealand forest industry about $\$ 58$ million per annum.

In order to understand whether selective tree breeding can be used to reduce spiral grain angle, research has been undertaken to quantify the heritability of this trait in radiata pine (Burdon and Low 1992; Jayawickrama 2001; Harris 1989; Gapare et al. 2007; Lindstrom et al. 2004). These studies found that the narrow-sense heritability of SGA in radiata pine ranged from moderate to high, which was consistent with research on other conifers such as Sitka spruce (Picea sitchensis (Bong.) Carr.) (Hansen and Roulund 1998) and Norway spruce (Picea abies Karst.) (Costa e Silva et al. 2000). A weak negative correlation between stem diameter and spiral grain has

\section{实}

(c) 2013 Watt et al.; licensee Springer. This is an Open Access article distributed under the terms of the Creative Commons Attribution License (http://creativecommons.org/licenses/by/2.0), which permits unrestricted use, distribution, and reproduction in any medium, provided the original work is properly cited. 
also been found indicating there may be some trade off in growth when reducing spiral grain angle through selective breeding (Jayawickrama 2001).

Characterisation of intra-tree variation in spiral grain angle has received considerably less attention in the literature than its genetic variability. In radiata pine, SGA generally declines from the innermost rings to about the 15th ring from the pith (Cown et al. 1991; Xin et al. 1996), while in the longitudinal direction there is generally an increase in SGA with height in the lower stem (Cown et al. 1991; Tsehaye and Walker 1995). Although circumferential variation in SGA has been noted in a single radiata pine stem (Cown et al. 2010) the authors are unaware of any research that has investigated if there is a consistent circumferential influence on SGA for this species between trees. Similarly, little research has investigated how the magnitude of intra-stem variation in SGA differs between genotypes.

Recent advances in measurement techniques (Brännström et al. 2008; Ekevad 2004) now mean that it is possible to assess the three-dimensional pattern of SGA within a stem. This paper reports on a study in which detailed measurements of SGA were made on 12 selected genotypes of radiata pine, aged seven years old. The objectives of this study were to characterise three-dimensional within-stem variation in SGA and identify whether intrastem variation in SGA varied between genotypes. Given the relatively small number of clones used in this study the objective of this work was not to describe fully the genetic effect but rather understand how intra-tree patterns might vary from genotype to genotype within a current breeding programme.

\section{Methods}

\section{Experimental design}

Data were collected between July 2008 and March 2009 from a radiata pine clonal variety trial at Esk Forest, Hawke's Bay, New Zealand (latitude 39.274 S, longitude 176.789 E, elevation $180 \mathrm{~m}$ ). The trial was established in 2001 as an incomplete block, single tree plot design, and consists of 42 plots each containing 48 trees planted at a $4 \times 4 \mathrm{~m}$ spacing (nominally 625 stems $^{-1}$ ). The site is in its second rotation of radiata pine. The trial has been pruned in three lifts, occurring between 2005 and 2007, to a height of around $6 \mathrm{~m}$. Hydrated sodium calcium borate hydroxide (Ulexite) was applied in 2005 at a rate of $6 \mathrm{~kg} \mathrm{ha}^{-1}$ in response to a foliar boron deficiency but no other applications of fertiliser were made. Over the trial period, this site has had a mean annual rainfall of $1500 \mathrm{~mm}$ and a mean annual temperature of $13^{\circ} \mathrm{C}$.

Twelve clones were selected (Mike Carson, pers. comm.) to span the range of available breeding values for diameter (at breast height), height, wood density, acoustic velocity, dothistroma resistance, branching, malformation and straightness. Selected clones also covered the range in outerwood densities and stress wave velocities (as assessed using a standing tree instrument). For each clone, two ramets were randomly selected giving a total of 24 trees for measurements.

The mean (and range in brackets) for diameter at breast height, height and crown mass of the selected trees were respectively $20.95 \mathrm{~cm}(17.6-24.3 \mathrm{~cm}), 13.25$ $\mathrm{m}(11.7-16.5 \mathrm{~m})$ and $66.2 \mathrm{~kg}(29-146.2 \mathrm{~kg})$.

\section{Measurements}

Each selected tree was felled then cut into sequential, parallel $30-\mathrm{mm}$ discs from the butt to a top diameter of approximately $50 \mathrm{~mm}$. A single disc was retained for spiral grain measurements from each annual growth unit meaning that discs were taken at approximately $1.8 \mathrm{~m}$ intervals up each stem from a height of about $0.3 \mathrm{~m}$ to a height of $7.6 \mathrm{~m}-12.0 \mathrm{~m}$ depending on the height of the tree, i.e. from 5 to 8 (average 6.6) discs per tree. These discs were selected to avoid grain deviation around branches. The discs were kiln dried under conditions of $60^{\circ} \mathrm{C}$ dry bulb $/ 56^{\circ} \mathrm{C}$ wet bulb to a moisture content of between 18 and $25 \%$. They were then further conditioned at $25^{\circ} \mathrm{C}$ and $65 \%$ relative humidity for $2-3$ weeks, resulting in an equilibrium moisture content of approximately $10 \%$. Four equally-spaced, 25-mm-wide, radial strip samples (in the N, E, S and W directions) were cut from each disc.

Spiral grain was measured at $5 \mathrm{~mm}$ intervals along each radial strip by exploiting the so-called "T2 effect" (McGunnigle 2009; Marschner et al. 2005; Matthews and Soest 1984). Due to the cellular nature of wood, light specularly reflected from a wooden surface is scattered in amounts that differ with fibre direction. By measuring the relative reflected intensities over a range of directions, the grain orientation vector (usually expressed as a pair of surface and dive angles) can be estimated. Careful surface preparation is critical to the success of this technique, since it relies on the microscopic texture and any preparation that alters the nature of this surface (e.g. sawing) will influence the results (Shen et al. 2000; Eastin and Johnson 1993). For this study, surfaces were first sawn then hand planed with a carefully honed blade.

A red laser ( $635 \mathrm{~nm}, 5 \mathrm{~mm}$ spot size) was projected at $90^{\circ}$ to the longitudinal-radial surface of the radial strips. The laser was moved from pith to bark along each radial sample in $5 \mathrm{~mm}$ steps. The raw surface (i.e. deviation from vertical in the longitudinal-radial plane) and dive (i.e. deviation from vertical in the longitudinal-tangential plane) angles were obtained from the specular reflection peaks. A peak-fitting algorithm was used to find peak locations based on the intersection of the maximum slopes. Analyses were carried out on grain values in 
relation to distance from the pith - not annual rings as in most previous studies.

Previous experience indicates that tilt correction significantly reduces the observed variation in spiral grain (Cown et al. 2010). Consequently, tilt adjusted values of surface and dive angle were also calculated, where surface angles from adjacent radii were used to adjust the measured dive angles. The tilt adjustment was carried out using the radii averages. The surface angle averages for the $\mathrm{N}$ and $\mathrm{S}$ radii were adjusted (by rotating the disc mathematically) to make the $\mathrm{N}$ and $\mathrm{S}$ radii equal and opposite in sign with the corresponding adjustment of measured dive angles in the E and $W$ radii. Similarly E and $\mathrm{W}$ radii were used to adjust the $\mathrm{N}$ and $\mathrm{S}$ dive angles.

The most common convention is to consider the lefthand, or "S" pattern (as viewed from the bark side) as a positive angle and right-hand " $Z$ " pattern as negative (Harris, 1989) and this was adopted for this study.

\section{Analyses}

Data were analysed using R (R Development Core Team 2011) and SAS Version 9.2 (SAS-Institute-Inc. 2000). An initial exploratory analysis was conducted using graphical procedures. These were used to examine the raw data, the probability distribution of SGA, and to produce box plots showing within- and between-tree variation in SGA. Means, standard deviations, and skewness and kurtosis parameters were calculated for each tree, and compared between clones using a one-way analysis of variance (ANOVA).

To determine how SGA varied within a typical stem, the following random coefficients mixed effects model was fitted using the MIXED procedure:

$$
S G A_{i j}=a_{i}+b_{i} h_{i j}+c_{i} d_{i j}+e_{i j}
$$

$$
\text { where, } \begin{aligned}
i & =\text { tree }(1, \ldots, 24) \\
j & =\text { sample within tree } \\
S G A_{i j} & =\text { grain angle of the } i{ }^{\text {th }} \text { sample } \\
h_{i j} & =\text { height within stem of the } i j^{\text {th }} \text { sample } \\
d_{i j} & =\text { distance from pith of the } i j^{\text {th }} \text { sample }
\end{aligned}
$$

In this model, $a_{i}, b_{i}$ and $c_{i}$ were assumed to vary between tree and to be independent identically distributed normal variables with means $\alpha, \beta$ and $\gamma$ respectively, and with an unstructured covariance matrix, while $e_{i j}$ is a randomly distributed error term. When fitting this model, the independent variables were standardised by subtracting their approximate mean values. Thus, 50 $\mathrm{mm}$ was subtracted from distance from pith, and $3 \mathrm{~m}$ subtracted from height within the stem. The effect of this approach was to make the random intercept term correspond roughly to a random mean for each tree. The model was used to test whether grain angle varied significantly in either the radial or longitudinal directions within a typical stem (by testing whether $\beta$ or $\gamma$ differed significantly from zero). Nonlinear and interaction effects were also modelled by adding and testing the significance of quadratic and interaction terms to Model (1).

To test for differences in grain angle between circumferential direction $(\mathrm{N}, \mathrm{S}, \mathrm{E}, \mathrm{W})$, mean grain angle was calculated by direction and tree, and a two-way ANOVA fitted with terms for tree and direction.

\section{Results}

In general, the two ramets of each clone exhibited similar patterns of SGA (Figure 1) although there were some notable exceptions (e.g. clone 809, growth unit 6). Likewise, the four radii measured on each disc often exhibited similar trends although again there were notable exceptions (e.g. clone 719, growth unit 4, ramet 2). The generally acknowledged average radial trend in SGA, namely near zero close to the pith followed by a rapid increase and subsequent decrease (Lausberg et al. 1995), was found within individual discs (e.g. clone 708, growth unit 5). However, in general, the radial patterns showed a great deal of variability. It is worth noting though that in no case was SGA observed to initially decrease (i.e. become increasingly right-handed).

Overall, SGA was approximately symmetrically distributed with a mean of $3.29^{\circ}$. Compared with a reference normal distribution, the grain angle distribution had long tails, and therefore a high coefficient of kurtosis (Figure 2, Table 1). The extreme values in the tails of the distribution could be largely eliminated by trimming the highest and lowest $0.4 \%$ of values from the distribution. All subsequent analyses were performed using both raw and trimmed data, but as results were very similar for both, only the results for the former are reported. Spiral grain angle was an extremely variable property with a coefficient of variation of nearly $100 \%$. Therefore, in order to obtain a robust estimate of the mean value of SGA for a tree or log using this technique, a large number of measurements are required. For example, to achieve an estimate of the mean with a standard error of $10 \%$ of this value, 90 measurements would be required. In this study, there were on average 2,800 measurements per tree, ensuring that mean grain angles could be quantified very precisely at both the intra- and inter-tree levels.

Mean values of SGA varied significantly between clones (Table 1). Exploratory analysis of within-tree trends in grain angle indicated a trend of increasing angle with height within stem levelling off above $5 \mathrm{~m}$ (Figure 3a), a radial trend showing an increase in grain angle over the first $20 \mathrm{~mm}$ followed by a gradual decline (Figure 3b), but no consistent directional effect (data not 


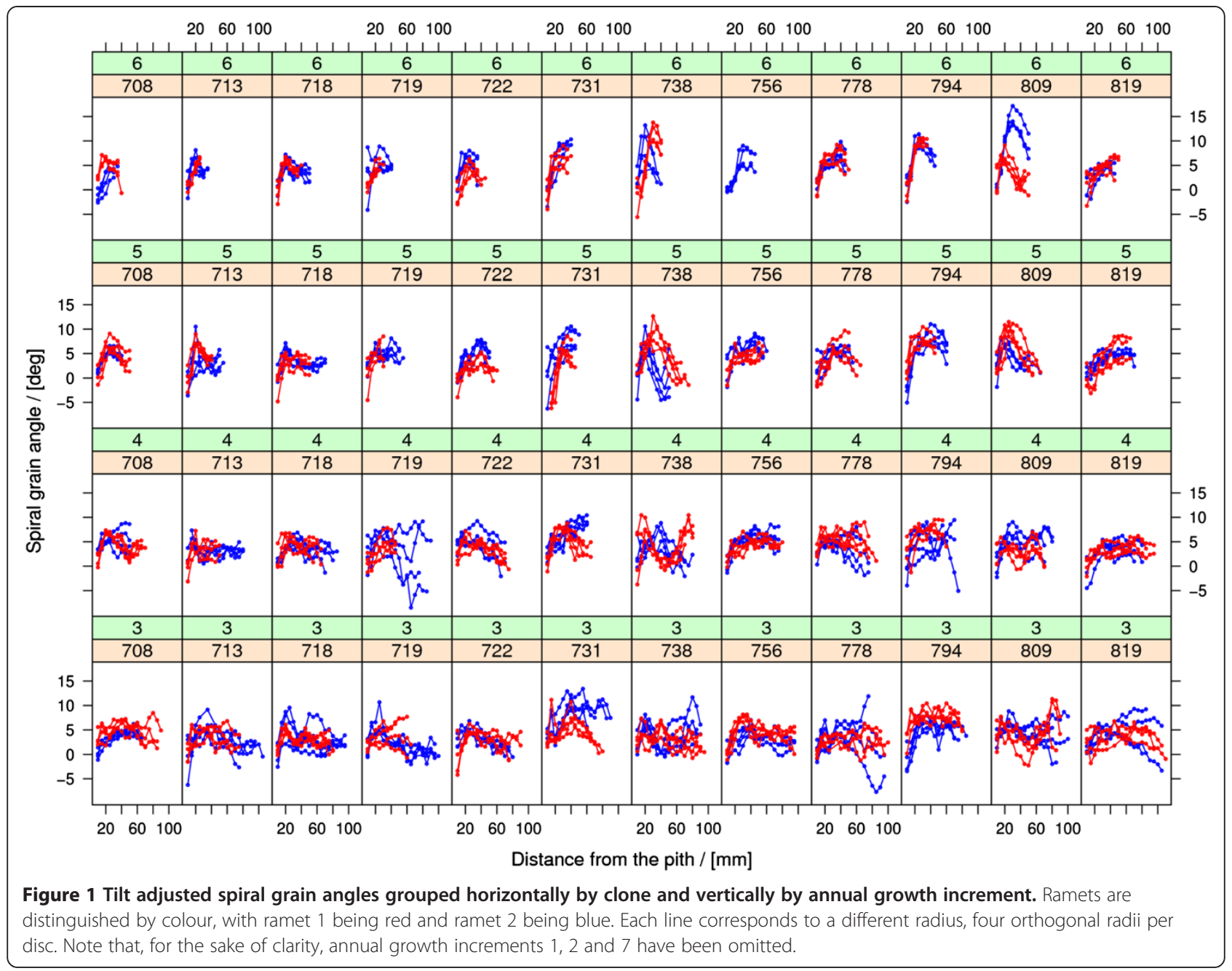

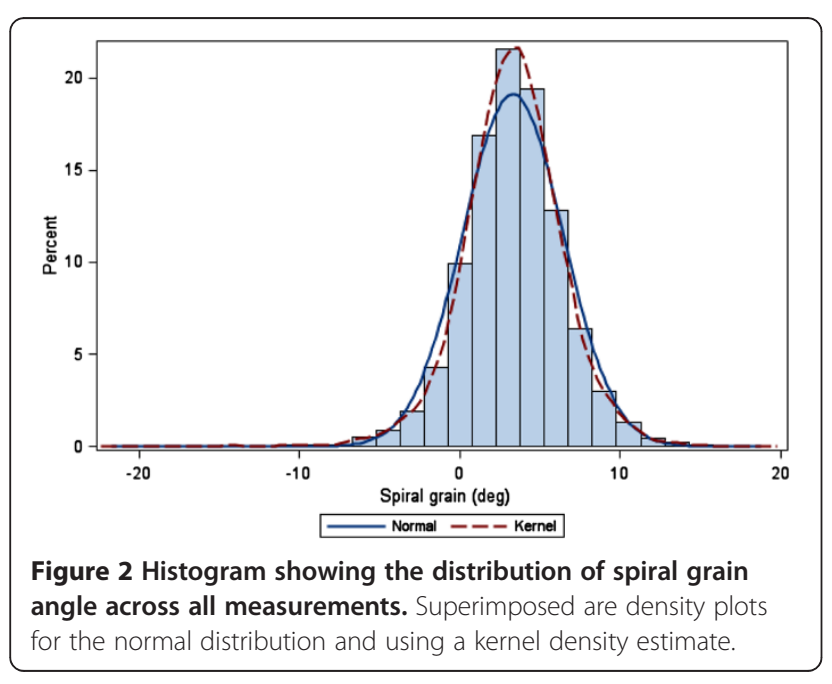

shown). Figure $3 \mathrm{c}$ shows the variability in grain angle by clone and tree, and demonstrates that the significant clonal differences observed $(P=0.0026$; Table 1$)$ mostly resulted from several (2 or 3 ) clones with higher than average values of SGA, with little difference between remaining clones.

Table 1 Distributional statistics of spiral grain angle

\begin{tabular}{llll}
\hline Statistic & Value & F-value & $\boldsymbol{P}$-value \\
\hline Mean & 3.29 & 5.81 & 0.0026 \\
Standard deviation & 3.13 & 2.36 & 0.078 \\
Coefficient of skewness & -0.32 & 4.60 & 0.0070 \\
Coefficient of kurtosis & 2.58 & 2.66 & 0.053 \\
\hline
\end{tabular}

The mean, standard deviation, and coefficients of skewness and kurtosis were calculated for each tree using all measurements and tested for clonal differences. Shown are the mean value for each statistic, and $F$-values (11 and 12 degrees of freedom) and corresponding $P$ values in tests for clonal differences. 


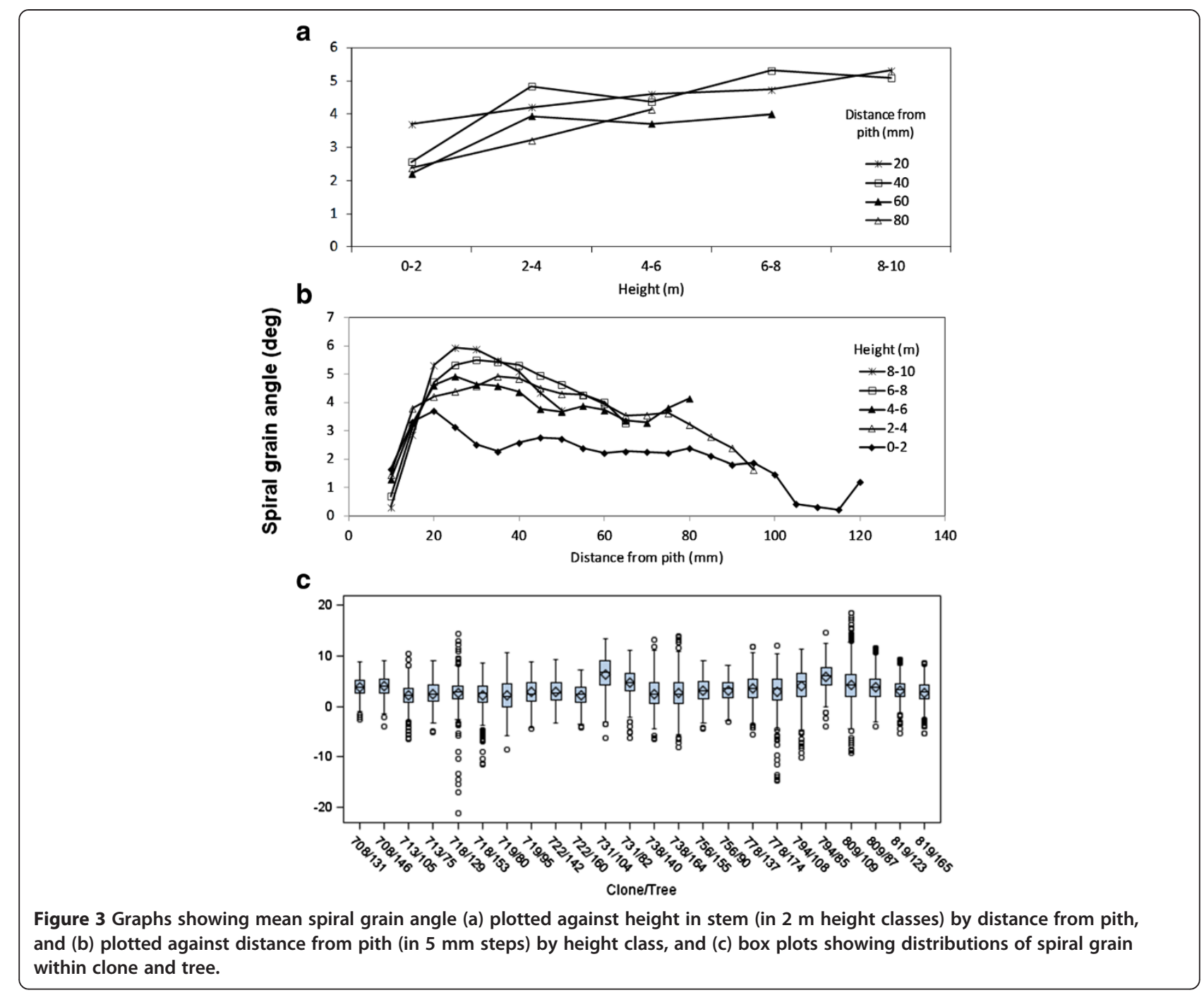

Analysis of variance confirmed that, within a tree, there was no significant difference in SGA between the four radial directions $\left(F_{26,69}=0.44, P=0.72\right)$. The effects of the remaining two within-tree directions (longitudinal and radial) were investigated using a random coefficient model similar to Model (1). Because grain angle increased rapidly in the inner $20 \mathrm{~mm}$ from the pith (Figure 3b), a strong effect apparent in all 24 trees in the study, measurements made 10 and $15 \mathrm{~mm}$ from the pith were excluded when fitting the random coefficient model. The model fitted to the measurements $20 \mathrm{~mm}$ or more from pith had significant terms for height within stem, distance from pith, and squared height (Table 2). A quadratic term for distance from pith and an interaction term between distance and height were tested but found to be not significant $(P>0.05)$. Parameters for individual trees were tested for clonal differences. The intercept was found to vary significantly a result in general agreement with the significant clonal differences for mean SGA shown in Table 1. However, the

Table 2 Estimates of parameters for the random coefficient model

\begin{tabular}{crrrr}
\hline Term & Estimate & Std. error & t value (23 d.f.) & \\
\hline Intercept & 3.82 & 0.27 & 14.31 & $<$ value \\
(Height-3) $(\mathrm{m})$ & 0.438 & 0.052 & 8.49 & $<0.0001$ \\
(Height-3) & -0.0410 & 0.0075 & -5.49 & $<0.0001$ \\
Distance from pith (mm) & -0.0154 & 0.0044 & -3.47 & 0.0021 \\
\hline
\end{tabular}

Shown are standard errors, $t$ values and corresponding $P$ values. 
terms for height and distance from pith and the quadratic height term did not differ significantly between clones. This indicates that clonal effects were confined to differences in the mean value of SGA, and that the within-tree patterns did not vary significantly between these clones.

Predictions for each tree from the model are shown in Figure 4. These show clear trends in mean SGA in both the radial and longitudinal dimensions for the majority of trees. One or two trees showed abnormal patterns but these were from different clones. The model shows a general trend for SGA to decrease linearly with distance from pith (beyond the inner $20 \mathrm{~mm}$ ), and to increase with height in the lower $5 \mathrm{~m}$ of stem and to stabilise beyond this height.

\section{Discussion}

Spiral grain angle is a complex wood property and comprises two distinct components that include the grain direction and magnitude of the gradient. The positive (or left handed) mean value of $3.29^{\circ}$ found here broadly agrees with the range found in other studies on radiata pine, where values range from $2.9^{\circ}$ to $4.7^{\circ}$ (Tsehaye and Walker 1995; Cown et al. 1991; Gapare et al. 2007). Values of SGA found in radiata pine regularly exceed mean values of $2^{\circ}$ found for Pinus taeda (Zobel et al. 1968), and $1.4^{\circ}$ to $2.7^{\circ}$ for Picea abies (Costa e Silva et al. 2000), but are relatively similar to mean values of $3.6^{\circ}$ for Araucaria cunninghamii (Eisemann et al. 1990) and $5^{\circ}$ for Picea sitchensis (Hansen and Roulund 1998). It is worth noting that, for wood utilisation, the mean value is not as important as the variation in SGA as twist results from differential SGA within the same board. The intra-tree variation in SGA was found to be very high, which agrees with results from previous research on the within tree distribution of SGA (Cown et al. 1991).

Consistent with the findings of this study, the high variation in SGA within trees has been shown previously to exhibit certain patterns, but these patterns are known to differ between tree species (Harris 1989; Aebischer and Denne 1996; Bäckström and Johansson 2006; Bannan 1966; Danborg 1994; Elliott 1985; Fujimoto et al. 2006). In trees
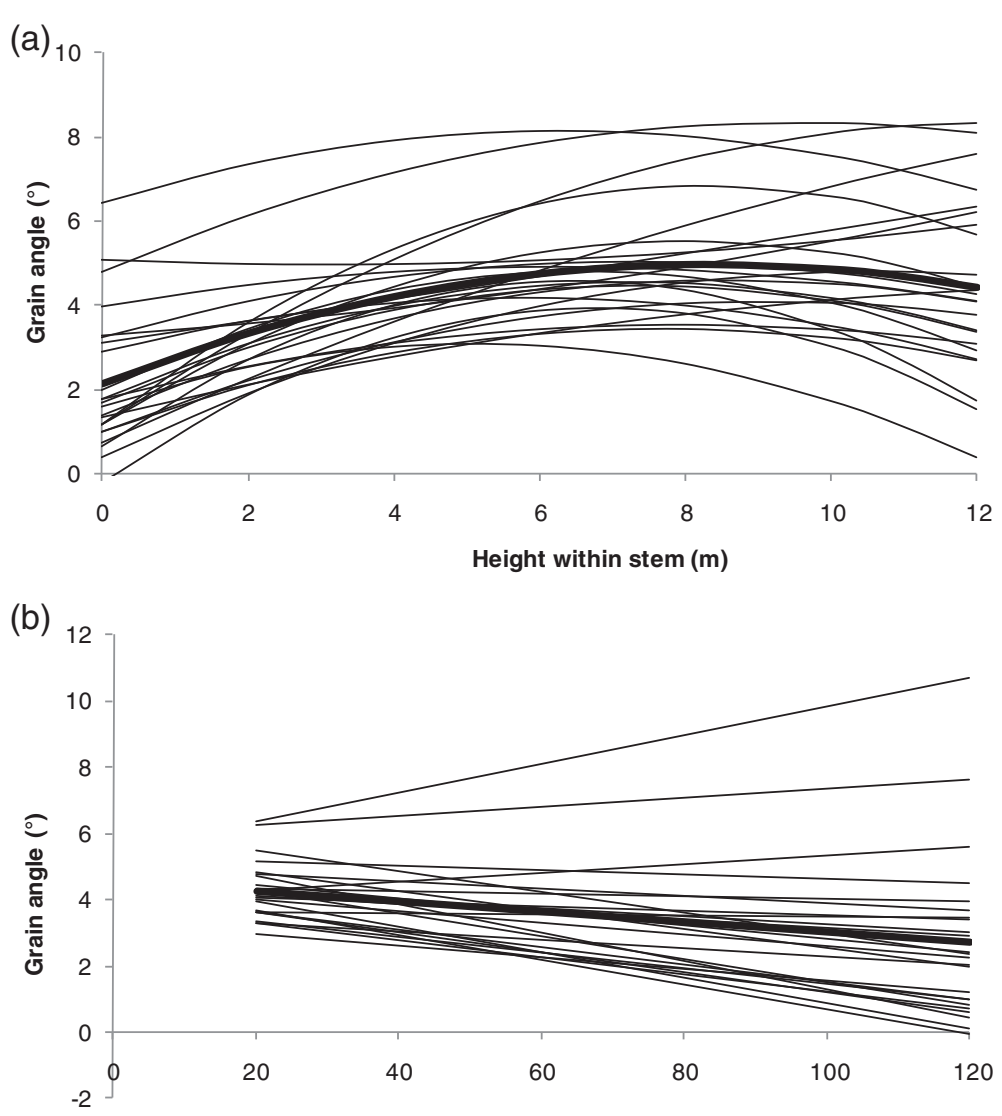

Distance from pith $(\mathrm{mm})$

Figure 4 Predicted spiral grain angle from the random-coefficient model with narrow lines representing individual trees, and the bold line representing the mean of all trees. Predictions are shown versus (a) height, at a fixed distance from pith of $50 \mathrm{~mm}$, and versus (b) distance from pith, at a fixed height of $3 \mathrm{~m}$. 
sampled from natural forests of Douglas-fir (Pseudotsuga menziesii (Mirb.) Franco) and western hemlock (Tsuga heterophylla (Raf.) Sarg), the highest values of SGA were found near the outside of the tree, where visible spiral grain causes timber degrade (McBride 1967). In contrast, highest values of SGA in radiata pine usually occur within the juvenile core, declining with distance, or ring number, from the pith (Cown et al. 1991; Tsehaye and Walker 1995).

Little systematic variation in SGA has been reported previously in the longitudinal direction (Cown et al. 1991; Tsehaye and Walker 1995) although a general small increase with height has been noted. In the current study, a significant increase in SGA was observed to a height of $5 \mathrm{~m}$ before it stabilised. These variations between studies may be attributable to the young age of the material studied here, which primarily shows longitudinal variation within the juvenile core, rather than variation over mature stems. This suggests that boards cut from the first log within the juvenile core may be subject to less twist, which agrees with previous sawing studies (Haslett et al. 1991). The age of the samples was too young to detect the normal transition with age from positive to negative values, which occurs after about 15 years (Cown et al., 1991). The results of the present study extend previous research by showing no consistent significant circumferential variation in SGA.

The major advance of this research is that it shows that three-dimensional within-tree variation in SGA pattern does not differ significantly among the clones tested. Further research is needed to confirm this result across a broader range of clones and sites. If found to be correct, this result will greatly simplify any further efforts to model within-tree variation in SGA as clonal effects can be treated as a simple offset in the model intercept. Given the young age of the material studied and the relatively low number of clones used within this study, further research should be undertaken to confirm this result. A tool recently developed (Riddell et al. 2012) will allow more detailed examination of withintree patterns and eliminate problems associated with sample alignment (with respect to stem axis).

\section{Conclusions}

The radial variation in SGA in radiata pine observed in this study was consistent with results from other studies in this and other conifer species. There was no consistent significant circumferential variation in SGA and no significant differences in within-tree patterns in SGA between the clones studied. Differences in SGA between clones were limited to differences in mean values. This uniformity of within-tree patterns of SGA between clones may greatly simply efforts to model three-dimensional variation in SGA.
Competing interests

The authors declare that they have no competing interests.

\section{Authors' contributions}

MSW was the primary author. MOK undertook the data analysis. JH designed the study, extracted the raw data and undertook preliminary data analysis. MR constructed the experimental apparatus, surfaced samples, and made measurements. DJC assisted with the study design, writing and literature review. JRM was a secondary author. All authors read and approved the final manuscript.

\section{Acknowledgements}

We gratefully acknowledge the access to material and assistance provided by Mike Carson, Judy Hayes (Forest Genetics) and by Brian Garnett (PanPac). The work reported herein was funded by Future Forests Research Ltd.

\section{Author details}

${ }^{1}$ Scion, P.O. Box 29237, Fendalton, Christchurch, New Zealand. ${ }^{2}$ Scion, P.O. Box 3020, Rotorua, New Zealand.

Received: 13 February 2013 Accepted: 29 August 2013

Published: 10 Sep 2013

\section{References}

Aebischer, DP, \& Denne, MP. (1996). Spiral grain in relation to ring width and cambial age in European oak (Quercus petraea (Matt) Liebl and Q. robur L). Holzforschung, 50(4), 297-302.

Bäckström, M, \& Johansson, M. (2006). Analytical model of twist in Norway spruce (Picea abies) timber. Scandinavian Journal of Forest Research, 21(1), 54-62.

Bannan, MM. (1966). Spiral grain and anticlinal division in the cambium of conifers. Canadian Journal of Botany, 44, 1515-1538.

Brännström, M, Manninen, J, \& Oja, J. (2008). Predicting the strength of sawn wood by tracheid laser scattering. BioResources, 3, 437-451.

Burdon, RD, \& Low, CB (1992). Genetic survey of Pinus radiata. 6. Wood properties: variation, heritabilities, and interrelationships with other traits. New Zealand Journal of Forestry Science, 22, 228-245.

Costa e Silva, J, Borralho, NMG, \& Wellendorf, H. (2000). Genetic parameter estimates for diameter growth, pilodyn penetration and spiral grain in Picea abies (L.) Karst. Silvae Genetica, 49, 29-36.

Cown, DJ, Young, GD, \& Kimberley, MO. (1991). Spiral grain patterns in plantation-grown Pinus radiata. New Zealand Journal of Forestry Science, 21, 206-216.

Cown, DJ, Walford, B, \& Kimberley, MO. (1995). Cross-grain effect of tensile strength and bending strength of Pinus radiata structural lumber. New Zealand Journal of Forestry Science, 25, 256-262.

Cown, DJ, Harrington, J, Bourreau, D, Haug, J, \& Lee, J. (2010). Spatial variation in spiral grain: A single stem of Pinus radiata D.Don. New Zealand Journal of Forestry Science, 40, 211-224

Danborg, F. (1994). Spiral grain in plantation trees of Picea abies. Canadian Journal of Forest Research, 24(8), 1662-1671.

Development Core Team, R (2011). R: A language and environment for statistical computing. Vienna, Austria: R Foundation for Statistical Computing.

Eastin, IL, \& Johnson, JA. (1993). A surface preparation technique for enhancing grain angle measurements using reflected light. Forest Products Journal, 43(2), 61-65.

Eisemann, RL, Harding, KJ, \& Eccles, DB. (1990). Genetic parameters and predicted selection responses for growth and wood properties in a population of Araucaria cunninghamii. Silvae Genetica, 39, 5-6.

Ekevad, M. (2004). Method to compute fiber directions in wood from computed tomography images. Journal of Wood Science, 50(1), 41-46.

Ekevad, M. (2005). Twist of wood studs: dependence on spiral grain gradient. Journal of Wood Science, 51, 455-461.

Elliott, GK. (1985). Spiral grain in second growth Douglas fir and western hemlock. Forest Products Journal, 8, 205-211.

Fujimoto, T, Akutsu, H, Kita, K, Uchiyama, K, Kuromaru, M, \& Oka, K. (2006). Age trends of genetic parameters of spiral grain in hybrid larch F1 and implications for efficiency of early selection. Journal of Wood Science, 52(2), 101-106. 
Gapare, W, Hathorn, A, Kain, D, Matheson, C, \& Wu, H (2007). Inheritance of spiral grain in the juvenile core of Pinus radiata. Canadian Journal of Forest Research, 37(1), 116-127. doi:10.1139/X06-202.

Hansen, JK, \& Roulund, H. (1998). Spiral grain in a clonal trial with Sitka spruce. Canadian Journal of Forest Research, 28(6), 911-919.

Harris, JM (1989). Spiral grain and wave phenomena in wood formation. Berlin: Springer-Verlag.

Haslett, AN, \& McConchie, DL (1986). Commercial utilization study of radiata pine thinnings for sawn timber production. New Zealand: New Zealand Forest Service FRI Bulletin 16

Haslett, AN, Simpson, IG, \& Kimberley, MO. (1991). Utilization of 25-year-old Pinus radiata. Part 2. Warp of structural timber in drying. New Zealand Journal of Forestry Science, 21, 228-234.

Jayawickrama, KSS. (2001). Genetic parameter estimates for radiata pine in New Zealand and New South Wales: A synthesis of results. Silvae Genetica, 50(2), 45-53.

Johansson, G, Kliger, R, \& Perstorper, M. (1994). Quality of structural timberproduct specification system required by end users. Holz Als Roh-Und Werkstoff, 52, 42-48.

Lausberg, MFJ, Cown, DJ, McConchie, DL, \& Skipwith, J. (1995). Variation in some wood properties of Pseudotsuga menziesii provenances grown in New Zealand. New Zealand Journal of Forestry Science, 25(2), 133-146.

Lindstrom, H, Harris, P, Sorensson, CT, \& Evans, R. (2004). Stiffness and wood variation of 3-year old Pinus radiata clones. Wood Science and Technology, 38(8), 579-597.

Marschner, SR, Westin, SH, Arbree, A, \& Moon, JT (2005). Measuring and Modeling the Appearance of Finished Wood. Los Angeles, California: Paper presented at the Proc. SIGGRAPH 2005

Matthews, PC, \& Soest, JF (1984). Method for determining localized fiber angle in a three dimensional fibrous material. US Patent No. 4606645.

McBride, CF. (1967). Spiral grain losses cost B.C. industry $\$ 5$ million a year. British Columbia Lumberman, 53, 46-50.

McGunnigle, G. (2009). Estimating fibre orientation in spruce using lighting direction. IET Computer Vision, 3(3), 143.

Ormarsson, S, \& Cown, D. (2005). Moisture-related distortion of timber boards of radiata pine: Comparison with Norway spruce. Wood and Fiber Science, 37, 424-436.

Riddell, M, Cown, D, Harrington, J, Lee, J, \& Moore, J. (2012). Assessing spiral grain angle by light transmission- Proof of concept. IAWA Journal, 33(1), 1-14.

SAS-Institute-Inc. (2000). SAS/STAT User's Guide: Version 8. Volumes 1, 2 and 3 (p. 3884). Cary, North Carolina: SAS Institute Inc.

Shen, J, Zhou, J, \& Vazquez, O. (2000). Experimental study of optical scattering and fiber orientation determination of softwood and hardwood with different surface finishes. Applied Spectroscopy, 54(12), 1793-1804.

Sorensson, CT, \& Lausberg, MJF (1996). Towards genetic improvement of spiral grain in radiata pine. In M. J. Dieters, A. C. Matheson, D. G. Nikles, C. E. Harwood, \& S. M. Walker (Eds.), Tree improvement for sustainable tropical forestry. Proceedings of the QRFI/IUFRO Conference, 17 Oct. - 1 Nov. 1996, Caloundra, Queensland, Aust (p. 216). Queensland, Australia: Queensland Forestry Research Institute.

Tsehaye, A, \& Walker, JCF. (1995). Spiral grain in Canterbury Pinus radiata: within and between-tree variations and effect on mechanical properties New Zealand Journal of Forestry Science, 25, 358-366.

Xin, T, Cown, DJ, \& Lausberg, M. (1996). Modelling of radiata pine wood properties. Part 1: Spiral Grain. New Zealand Journal of Forestry Science, 25(2), 200-213.

Zobel, BJ, Stonecypher, RW, \& Browne, C. (1968). Inherirance of spiral grain in young loblolly pine. Forest Science, 14, 376-379.

10.1186/1179-5395-43-12

Cite this article as: Watt et al:: Differences in intra-tree variation in spiral grain angle for radiata pine. New Zealand Journal of Forestry Science 2013, 43:12

\section{Submit your manuscript to a SpringerOpen ${ }^{\circ}$ journal and benefit from:}

- Convenient online submission

- Rigorous peer review

- Immediate publication on acceptance

- Open access: articles freely available online

- High visibility within the field

- Retaining the copyright to your article

Submit your next manuscript at $>$ springeropen.com 